\title{
UM OLHAR SOBRE O SER MULHER NA DEMOCRACIA
}

\author{
Kamyla Heleny Titara Martins
}

BIROLI, Flávia. Gênero e desigualdades: os limites da democracia no Brasil. 1 ed. São Paulo: Boitempo, 2018 .

A autora Flávia Biroli, brasileira, nascida em São José do Rio Preto, doutora em história, professora de Ciência Política na Universidade de Brasília, especialista em teoria política feminista e membro do Grupo de Assessoras da Sociedade Civil da ONU Mulheres, discorre na obra "Gênero e desigualdades: limites da democracia no Brasil", embasada em dados quantitativos e teóricos, as imposições sociais que dificultam mulheres de acessar a democracia.

O livro, publicado pela primeira vez em fevereiro de 2018 pela editora Boitempo, no estado de São Paulo, disserta em 238 páginas sobre cinco tópicos e em como esses ainda permanecem como amarras no que concerne ao acesso à cidadania. São eles: divisão sexual do trabalho; cuidado e responsabilidades; família e maternidade; aborto; sexualidade e autonomia; feminismo e política, seguido pela conclusão.

Desse modo, no primeiro capítulo a autora debruça-se sobre a questão de certas atividades serem consideradas próprias do sexo feminino, enfaticamente, trabalhos de âmbito doméstico, e ressalta que mulheres pobres, em sua maioria negras, estão a cargo dessa função. Discorre que as trabalhadoras possuem dupla jornada de trabalho, sendo a primeira remunerada e a segunda, por se tratar de cunho familiar, não remunerada, de tal maneira que a segunda jornada somente acarreta ônus, em nada contribuindo para o desenvolvimento pessoal ou intelectual dessas mulheres, visto a ausência de tempo ser a principal barreira para que isso ocorra. Aponta ainda que as mesmas mudanças são sentidas de maneiras distintas nos diferentes estratos sociais, pois, por exemplo, no caso da maternidade, a mulher de classe abastada pode contratar uma pessoa para cuidar de seu filho enquanto dedica-se ao trabalho, ao passo que esse mesmo cenário é impossível para mulheres de classes mais baixas.

No segundo capítulo, ao tratar do tema cuidados e responsabilidades, Flávia Biroli apresenta uma questão por tantos ignorada, a imposição social de que as mulheres, seja no papel de mães ou filhas, por exemplo, possuam a obrigação de tornarem-se cuidadoras exclusivas de crianças ou familiares que, por qualquer motivo, necessitem de atenção integral, pondo essas cidadãs em esquecimento, transfigurando-as em seres sem necessidades que vivem para suprir as carências de outrem. Acrescenta-se que a autora aborda a ausência de uma rede de cuidados, feita pela própria comunidade, e de creches escolares como um dos fatores que corroboram na necessidade do cuidado integral, impedindo que as mulheres nessas condições tenham acesso ao mercado de trabalho.

No terceiro capítulo, a autora discorre sobre as mudanças sociais ocorridas entre os séculos XX e 
XXI a respeito do casamento heteronormativo, instituído inicialmente como meio de estabilização financeira, visto as condições econômicas dos homens superarem em muito as das mulheres, ademais, serem considerados objetivo primordial da vida feminina, posto a imposição social da necessidade do matrimônio. Em seguida, teoriza a respeito do papel da maternidade no que tange à restrição da participação da mulher nas esferas sociais, pois a essa cabe o papel do cuidado, enquanto ao homem cabe o dever único de suprir as necessidades básicas da criança. Acrescenta a autora a respeito da negligência legislativa ao ditar normas e políticas sociais, pois, para ela, o legislador desconsidera as taxas de violência doméstica, abandono parental e demais máculas constantes na família brasileira.

Em seguida, ao discorrer sobre aborto, sexualidade e autonomia são apresentadas as mudanças históricas no que concerne aos direitos sexuais femininos, entretanto, também é relatada a chamada onda conservadora que incide na América Latina e os retrocessos legislativos concernentes ao tema em outras regiões, por exemplo, a criminalização do aborto terapêutico em Nicarágua, que anteriormente era legalizado. Ademais, insta remeter que a autora apresenta o fato de que o debate acerca dos direitos reprodutivos, por não se tratar de estender às mulheres direitos conquistados pelos homens, como o que ocorreu com o direito ao voto, reflete desigualdades e privilégios entre os diferentes estratos sociais, sendo necessário um olhar aprofundado sobre a temática para que haja políticas públicas efetivas, que atendam às necessidades de mulheres de diferentes classes.

No penúltimo capítulo, intitulado de "feminismo e política", é apresentado um contexto histórico, com enfoque no período de redemocratização após a ditadura de 1964 e formulação da Constituição de 1988, em que as mulheres buscaram efetivar direitos sexuais e reprodutivos, buscando debater sobre o aborto, porém, devido ao caráter conservador dos políticos brasileiros, tal assunto extinguiu-se durante o período da constituinte, do rol de direitos constitucionais.

A autora apresenta o viés misógino da política em que, mesmo com as cotas partidárias, as mulheres ainda são poucas na política, atuando como mero enfeite para o alcance de interesses de outrem. A autora retorna a um assunto já apresentado anteriormente, que pela ausência de representatividade feminina no meio político demandas particulares do ser mulher tornam-se desprezadas, o que repercute na ausência de políticas públicas e de leis que, de fato, reverberem as necessidades femininas.

Por fim, nas conclusões, Flávia Biroli ratifica a importância dos feminismos no debate de imposições sociais e na aquisição de direitos no decorrer da história. Desse modo, embasada em obras das áreas de Ciência Política e Ciências Sociais, como teses, revistas, e livros, podendo ser ressaltados os nomes de Noberto Bobbio e Neuma Aguiar e em autoras feministas, como Simone de Beavouir, Flávia Biroli, na obra de caráter dissertativo-argumentativo, disserta sobre as adversidades que interferem o acesso à democracia por parte das mulheres, seja os percalços familiares quantos os impostos na vida em comunidade.

Acrescenta-se que a autora faz menção às mudanças históricas e, por isso, se utiliza de material bibliográfico dessa área. Sendo assim, pode-se afirmar que na obra são utilizados como métodos: a revisão bibliográfica e o método científico histórico, uma vez que a autora estuda as mudanças ocorridas na 
democracia e também deduz, a partir do material teórico e pesquisas quantitativas como por exemplo, as feitas pelo Ministério da Saúde a respeito dos impactos do aborto, que, de fato, não se pode afirmar que todos possuem os mesmos direitos e exercem a cidadania de maneira igualitária.

De tal modo, a obra nos leva a questionar os limites da democracia, forma de Estado instituída por meio de lutas e que sofreu diversos percalços até os dias atuais e instiga o leitor a aprofundar o olhar no que concerne às variantes que impedem à mulher de exercer seus direitos tal qual ocorre com os indivíduos do sexo masculino, dando azo a questionamentos que ultrapassam a questão do gênero e estão envoltos em dilemas que tangem classes sociais e cor da pele.

De fato, pode se afirmar que a inclusão da mulher na sociedade, como ser ativo, é deveras recente. A aquisição do direito ao voto somente ocorreu em 1965, pois em momento anterior havia limitações, como a necessidade da autorização do esposo, no caso de mulheres casadas, ou a obrigatoriedade de possuir uma renda própria, quando tratava-se de viúvas ou de mulheres solteiras. No Brasil, a primeira mulher senadora foi Eunice Michiles que assumiu a cadeira no Senado após a morte de João Bosco, no ano de 1978. Em entrevistas da época a ex-senadora relatou que foi por diversas vezes silenciada e ignorada por suas opiniões consideradas modernas para a época. Ainda como ocorre atualmente, as revistas se limitavam a opinar sobre o modo de se vestir e portar da senadora, esquecendo a esfera política e servindo como meio propagador de estereótipos femininos. Entretanto, como apontado pela autora Flávia Biroli, somente mulheres sabem as necessidades próprias de seu gênero e como pode a mídia questionar a ausência de mulheres na política, se essa é a primeira a silenciar suas opiniões diante de frivolidades?

Acrescenta-se que a inserção de mulheres na política, segundo estudos realizados nos Estados Unidos, Brasil e outros países latino-americanos, traz “agendas temáticas decisórias”, dando atenção a grupos de pouca visibilidade, tais quais idosos, deficientes, crianças e às próprias mulheres, auxiliando por tanto o desenvolvimento de camadas esquecidas socialmente (ALMEIDA; LÜCHMANN; RIBEIRO, 2012). Porém, como apontado por Flávia Biroli, estereótipos femininos tais quais "política é lugar de homem" limitam mulheres à participação social em sede de ONGs e grupos de bairros, fato que repercute socialmente, entrementes, poderia ser fortemente ampliado caso ocorre em âmbito nacional.

Acrescenta-se que quando mulheres são eleitas para exercer cargos políticos, anteriormente houve o patrocínio, na maioria das vezes, de homens que as auxiliaram na disputa visando a possuir apoio em suas decisões e propostas legislativas, incentivando dessa maneira candidaturas com discursos sociais, porém, drasticamente alterados após as eleições. Sendo assim, candidatas que se elegeram tendo como intuito suprir as necessidades do povo, são obrigadas a se alinharem aos interesses de seus padrinhos, desvirtuando-se do caráter democrático da política no Brasil.

Ao tratar a respeito de feminismos e da crescente onda conservadora na América Latina, a autora nos faz relembrar tempos de cerceamento de direitos, levando o leitor a temer pelo deslinde da política atual, pois, por exemplo, o atual presidente, Jair Bolsonaro, foi um dos idealizadores da Lei $\mathrm{n}^{\circ} 6.055$, de 2013, que visava revogar a Lei ${ }^{\circ} 12.845$, de $1^{\circ}$ de agosto de 2013 , que instituiu o serviço emergencial e multidisciplinar 
a vítimas de violência sexual. Um dos argumentos levantados foi que essa lei abria espaço para legalização do aborto no Brasil e que, em favor do povo brasileiro e de seus preceitos, tal medida deveria ser evitada. Atualmente, o projeto encontra-se arquivado.

Insta salientar que a limitação e a própria extinção de direitos não ocorrem de forma súbita, mas de maneira sutil. De tal modo, reitera-se a importância dos movimentos feministas no que remete aos direitos das mulheres e que mudanças legislativas, constitucionais ou administrativas referentes a esse grupo devem ser feitas mediante plebiscito e referendo, meios constitucionais que resguardam a participação popular e garantem que mulheres atuem ativamente em propostas que possuem impacto direto em suas vidas.

É importante frisar que, do mesmo modo que apenas mulheres podem expressar as necessidades próprias de seu gênero, somente cidadãs de classes sociais menos abastadas podem oralizar suas demandas, entretanto, essas são as mais silenciadas. O ano de 2020 foi marcado pelas eleições municipais e surge o questionamento de quantas mulheres das classes menos favorecidas foram ouvidas, quantos candidatos se dispuseram a questionar e propor medidas para assisti-las de modo a inseri-las na política para que suas necessidades fossem supridas.

É fato que sempre haverá questões a serem debatidas e modificadas, pois é utópico imaginar uma sociedade em que todos estejam plenamente satisfeitos. Entrementes, no Brasil, é visível o descaso social, meninas ainda na adolescência que se tornam mães devido à carência de educação sexual em casa e na escola e, como já fora mencionado, o conservadorismo tende a podar ainda mais o conhecimento a respeito de relações sexuais e de gênero. Em consequência, essas mães jovens, sem trabalho formal, não são incentivadas e não possuem tempo para desenvolver-se intelectualmente e profissionalmente, devido à falta de creches integrais e de redes de cuidado, como apontou a autora Flávia Biroli.

Desse modo, torna-se necessário que essas mulheres, nessas condições, apresentem de que maneira poderiam ser empregadas políticas públicas e de que modo lhes seriam mais úteis, porém, não há espaço para que tal assunto seja debatido e o problema cerne dessa questão é a ausência de mulheres na política e de espaços viáveis para esses debates.

Por fim, visando suprir essas carências cabe às instituições de ensino, sejam elas escolas ou universidades, incentivar meninas e mulheres a atuarem de modo efetivo na política, seja convidando mulheres em posições de cargos políticos para conversar com essas meninas ou fornecendo palestras que instiguem essas cidadãs a aprofundarem seu conhecimento a respeito dos impactos da mulher na política e da necessidade da participação feminina nesse meio.

Insta remeter que cabe ao poder público adotar programas sociais que deem às mulheres de pequenas comunidades visibilidade para que elas apresentem as demandas de sua região, posto que por muitas vezes são esquecidas. Acrescenta-se a importância da implementação legislativa que oriente aos gestores municipais a direcionar recursos econômicos a regiões menos favorecidas, tendo como fim incentivar a formação de pequenos empreendimentos, especificamente administrados por mulheres, visto que a dependência financeira é um dos principais motivos de permanência em relações abusivas e impede que 
mulheres se desenvolvam profissional e intelectualmente, sendo também um impasse ao acesso efetivo da democracia.

\section{REFERÊNCIAS BIBLIOGRÁFICAS:}

BIROLI, Flávia. Gênero e desigualdades: limites da democracia no Brasil. 1 ed. São Paulo: Boitempo, 2018.

LIMA, Juliana. Democracia no Brasil e participação das mulheres na política: algumas barreiras para o desenvolvimento democrático Porto Alegre, 2015 Disponível em: <https:/www.ufrgs.br/sicp/wp-

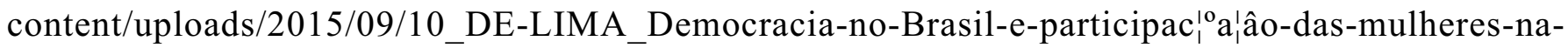
poli, ütica.pdf $>$ Acesso em: 31 out. 2020.

MEGALE, Bela. Bolsonaro pediu fim da lei que garante atendimento a vítimas de estupro. Época, 12 out. 2018.Disponível em: <https: //epoca.globo.com/ bela-megale/bolsonaro-pediu-fim-da-lei-que-garanteatendimento-vitimas-de-estupro-23152056>. Acesso em: 31 out.2020.

11 MULHERES pioneiras na política brasileira. As mina na história, 2018. Disponível em: $<$ https://asminanahistoria.com/2018/10/06/11-mulheres-pioneiras-na-politica-brasileira/> Acesso em: 31 out. 2020 . 